\title{
Overcrowding of accident \& emergency units: is it a growing concern in Nigeria?
}

\author{
Jerry G Makama ${ }^{1}$, Pius Iribhogbe ${ }^{2}$, Emmanuel A Ameh ${ }^{1}$
}

1. Ahmadu Bello University Teaching Hospital Zaria, Nigeria, Surgery

2. University of Benin Teaching Hospital Benin, Department of Surgery

\begin{abstract}
Background: The inability of the Nigeria's Accident and Emergency Departments (AED) to meet current demands is growing among the public and health care professionals. The data supporting perceptions of insufficient capacity are limited. Therefore, this study was intended to determine the prevalence, causes, and effects of overcrowding AEDs in Nigeria.

Materials and Methods: This was a cross sectional, descriptive study carried out among AED staff of 3 referral teaching hospitals in Nigeria, using a pre-tested and validated structured questionnaire.

Results: The analysis of the 267 AED staff revealed 20-56years (36.40+5.1 mean) age range. One hundred and twenty eight $(47.9 \%)$ were males, 139 (52.1\%) females. Two hundred and fifty nine (97\%) agreed that an AED should have a bed capacity of 21-30. Agreement to AED overcrowding in Nigeria was quite considerable. The frequency of AED overcrowding per week was 4-7 times. The average bed occupancy level was 3.25. Agreed common causes of prolonged AED admissions were to be a high volume of critically ill patients, Delayed transfer of patients to the wards, delay in theatre operation, delay in radiological investigations and exceptionally high proportion of patients requiring admission in AED. Also, long pre-review waiting time and haematological delays were more causes. The average waiting time for victims to be seen was $29.7 \mathrm{minutes}$. Conclusion: There are many causes of AED overcrowding in this environment. However, improving AED bed management, better organized and diligent discharge planning, and reducing access block should be a priority to reduce AED overcrowding
\end{abstract}

Keywords: Overcrowding, accident, emergency surgery, Nigeria

DOI: http://dx.doi.org/10.4314/ahs.v15i2.20

\section{Introduction}

Hospital Emergency departments maintain a highly strategic position in the continuum of medical care, in every society ${ }^{1}$. Emergency departments (EDs) are a critical component in health care, available 24 hours a day, 7 days a week, particularly for all who require acute care $^{1,2}$. Accessible and always available, the ED remains one of the few institutions available to assist all persons. Its services are provided regardless of economic or social status and without an appointment. Accident and Emergency Department (AED) overcrowding has been an increasingly serious health problem for more than a

\section{Corresponding author: \\ Jerry G Makama \\ Ahmadu Bello University Teaching \\ Hospital Zaria, Nigeria, Surgery \\ Email: jerlizabeth@yahoo.com}

decade $^{2,3}$. The inability of the Nigeria's emergency departments to meet current demands is growing among the public and health care professionals. This rise in AED utilization has effectively saturated the capacity of AEDs and emergency medical services in many communities. The resulting phenomenon, commonly referred to as AED overcrowding, now threatens access to emergency services for those who need them the most $t^{4,5}$.

AED overcrowding is a clear, almost inevitable indicator of steadily growing demand that has exceeded available resources ${ }^{3}$. Surprisingly, this saturation of emergency services is not usually a result of excessive, inappropriate use of the AED by those with nonemergent problems. It is a byproduct of increasing numbers of patients with serious illnesses or injuries requiring hospital and/or intensive care unit admission ${ }^{2-5}$. AED overcrowding is an increasingly difficult impediment to access emergency care, causing loss of patient privacy and confidentiality, delays in receiving care and time sensitive treatments, patient departure prior to the completion of care and staff and patient dissatisfaction ${ }^{5}$. The 
facts supporting perceptions of insufficient capacity are unit where accident/trauma victims in the entire Midand effects of overcrowding in the AEDs in Nigeria.

\section{Material and methods}

Study design

This was a cross sectional, descriptive study that was carried out among employees of AEDs in three major, referral teaching hospitals of Nigeria. The research design consisted of a questionnaire distributed to the member institutions of the Ahmadu Bello University Teaching Hospital Zaria, University of Benin Teaching Hospital Benin and University of Jos Teaching Hospital Jos.

\section{Study Setting and Population}

Ahmadu Bello University Teaching Hospital

(ABUTH) Zaria was established in1967. It was formerly known as the institute of health. The statue 15 of the university law (amendment act, schedule 16) by the then acting public services office of the former northern Nigerian Government established it. The main objective was to provide facilities for the training of doctors and other professionals allied to medicine, primarily for the then northern region. In 1976, the federal government took over all the teaching hospitals in the country including institute of health, Zaria. The institute of health was affiliated to Ahmadu Bello University Zaria. In 1985, the Ahmadu Bello University teaching hospital became legally and operationally separated from the University. It started with a casualty unit which was used to handle only trauma casualties but currently, it is operating as an Accident and Emergency Unit since November 2005. The hospital has a 500 bed capacity serving the North West region of Nigeria. The Accident \& Emergency manages over 7,600 AED Patients every year. It also provides necessary facilities for training of senior and intermediate level manpower for the health industry and spearheads research opportunities for lecturers in the Ahmadu Bello University.

University of Benin Teaching Hospital (UBTH) is a tertiary health facility that came into being in 1973 following the enactment of an edict (number 12). It was established to complement her sister institution, University of Benin, and also, to provide secondary and tertiary care to the then Midwestern Region (now Edo and Delta State) and its environs. The teaching hospital has an exceptionally strong accident \& emergency bed tertiary hospital in Jos, the Plateau state capital in north central Nigeria. JUTH provides a measure of emergency, inpatient and outpatient services. These include surgical, emergency/trauma, obstetrical, gynaeco-

logical, paediatric, psychiatric services, medical services

and laboratory services.

All these are tertiary care academic medical centers in urban setting. The academic medical centers include both adult and pediatric AED's, and all subsequent discussion in this paper will pertain specifically to the adul and paediatric AED. The study period was defined a the six-month period lasting from September 1,2010 to February 28, 2011. The first two months were used as the training period, and the last four months were used as the time of data collection. The local Institutional Review Board approved this research.

\section{Data collection}

Operational data was obtained from hospital databases; from staffing schedules of attending, residents, and nurses. The use of a structured questionnaire to determine the actual capacity of the AED, whether it can sometimes become crowded, how many time does it get crowded. The questionnaire also asked respondents to indicate their level of agreement with regards to common causes of AED overcrowding in the environment using linkert scale from strongly agreed - strongly disagree. Data was collected on levels of frustration by staff and patients and its outcomes on emergency medical care. AED overcrowding was defined for the purpose of this study as "all AED bed spaces (capacity) occupied but, in addition have patients on floor, patients on couches, trolleys and wheel chairs, full, waiting rooms, full hallways, acutely ill patients waiting $>60$ minutes to see a physician.

Bed occupancy level was defined as the number of patients in the treatment area divided by the number of
Jos University Teaching Hospital (JUTH) is a 500 licensed AED beds. This value may exceed 100\% when patients are doubled in rooms or placed in a hallway.

\section{Data preparation}

All data was cleaned. Processing and simple analyses were performed with SSPS (version 17.5)

Results:

A total of 281 questionnaires [ABUTH:119(42.3\%), UBTH:112 (39.9\%), and JUTH: 50(17.8\%)] were distributed to staff and residents on clinical rotation to accident \& emergency departments of the three teach-

ing hospitals that participated in the study. A total of fourteen questionnaires were not properly filled and so they were excluded leaving 267. Of these two hundred and sixty seven respondents, the following proportions were considered as valid responses from each center [ABUTH: 112(41.9\%), UBTH: 108 (40.4\%), and JUTH: $47(17.6 \%)$.

The analysis of the 267 revealed an age range of respondents to be 20-56 (36.40+5.1 mean). One hundred and twenty eight (47.9\%) were males while $139(52.1 \%)$ were females. Part of the category of participatory professionals in the study included doctors and nurses (figure 1).

Figure 1: The category of Professional among respondents

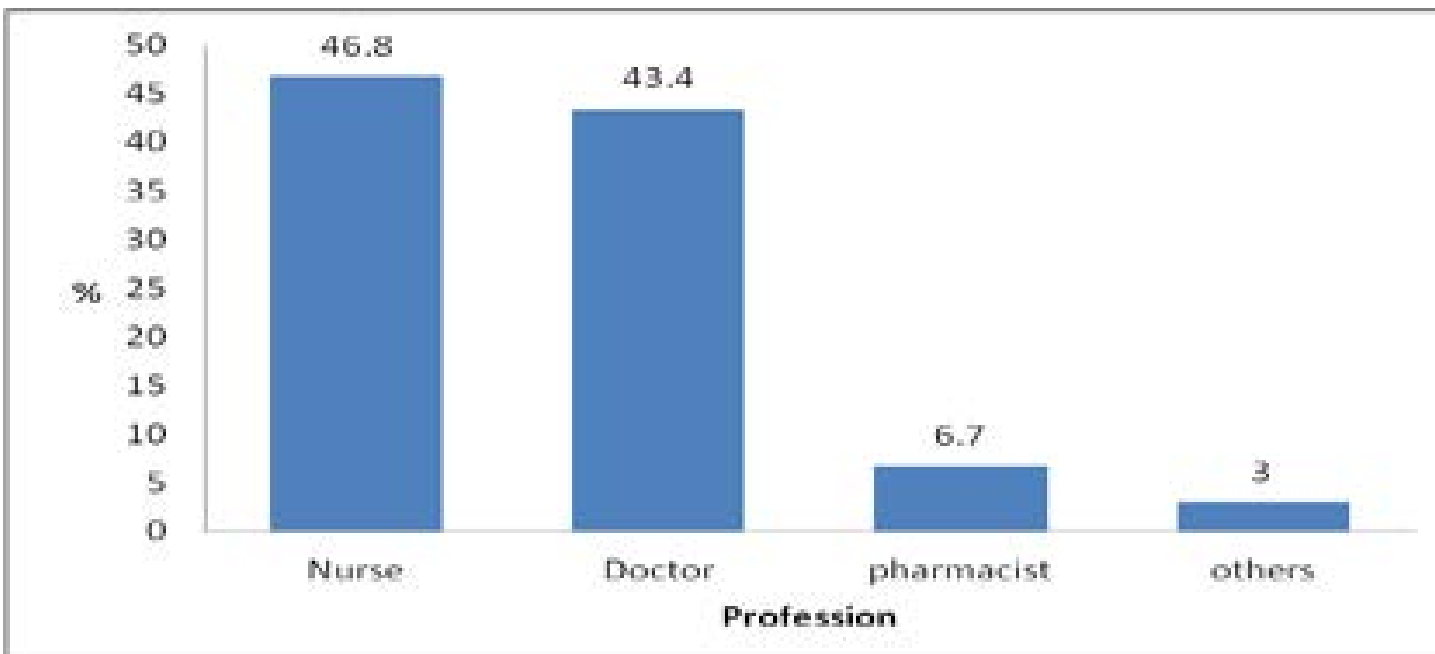

The majority of the respondents agreed that an AED should not exceed a bed capacity of 21-30 (figure 2).

Figure 2: The AED bed capacity

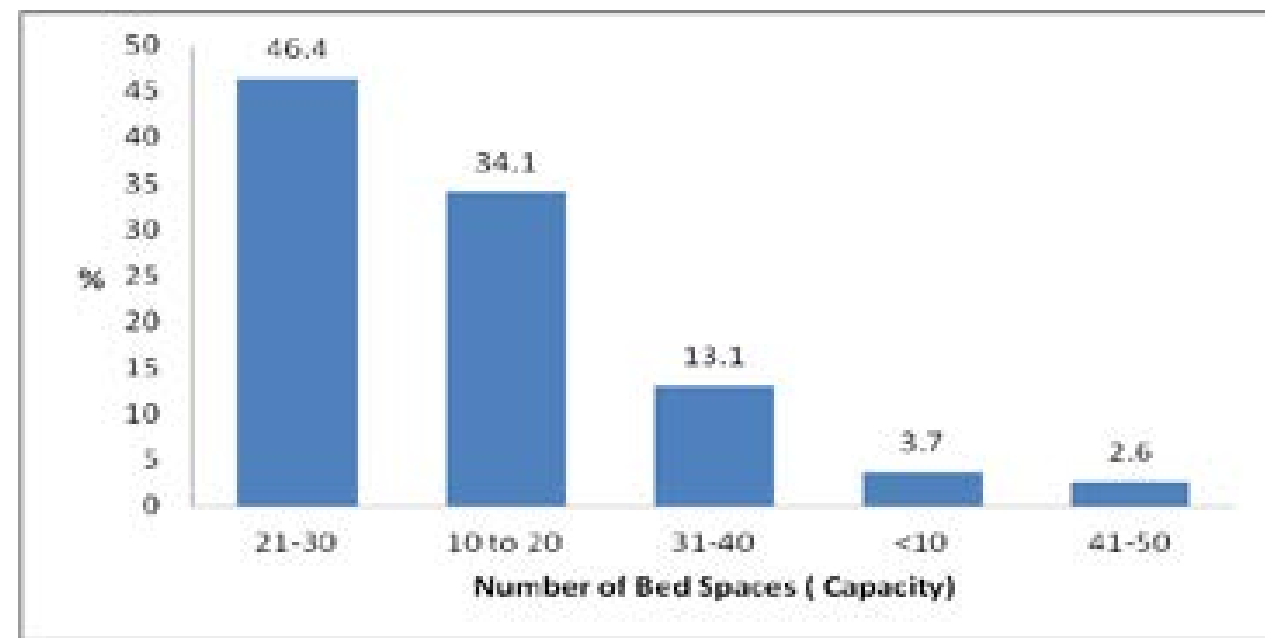


Figure 3: The level of acceptance for AEDs overcrowding in Nigeria

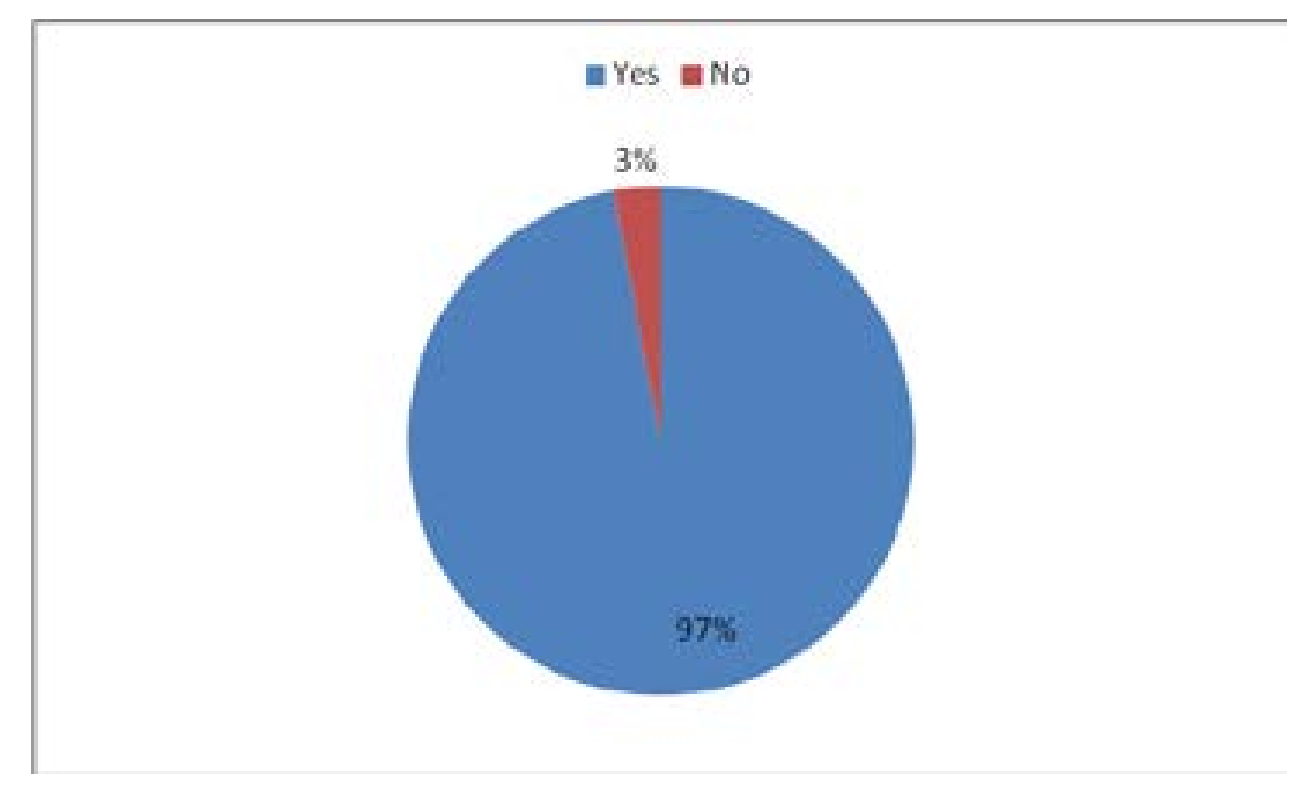

Ninety seven percent of the respondents agreed that ied. . The frequency of AED overcrowding in a week overcrowding occurred in AEDs of the hospital stud- was between 4-7 times (Figure 4).

Figure 4: The frequency of AED overcrowding per week

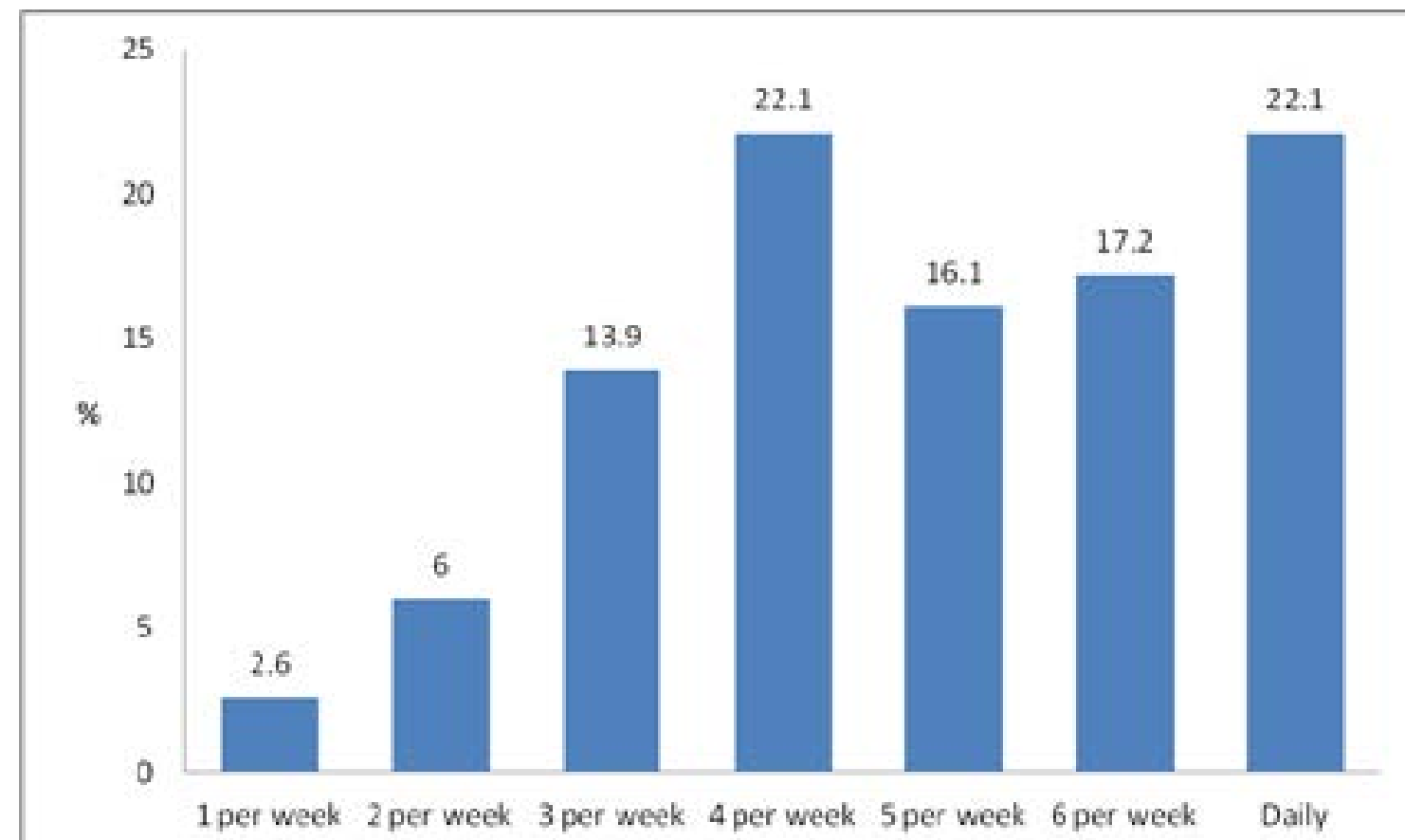

Frequency of AED overcrowding per week
The bed occupancy rate was 99.4\% while the average wheel chairs (1.9), trolleys (2.7), and floors (2.1).

bed occupancy level was 3.25. The average number of Common causes of prolonged AED admissions were non bed patients per week was 9.77 (couches (3.07), as in Table 1).

Table1. Common causes of long AED admissions

\begin{tabular}{|l|l|l|l|}
\hline S/No & Cause & Value & Percentage \\
\hline 1 & Delay theater operations & 34 & 12.3 \\
\hline 2 & Delay transfers of patients to wards & 57 & 21.3 \\
\hline 3 & $\begin{array}{l}\text { Delay in haematological } \\
\text { investigations }\end{array}$ & 29 & 10.8 \\
\hline 4 & Long pre-review waiting period & 24 & 9.0 \\
\hline 5 & Delay in radiological investigations & 32 & 12.0 \\
\hline 6 & Poverty & 21 & 8.0 \\
\hline 7 & Absent community health officers & 27 & 10.1 \\
\hline 8 & High burden of road traffic accident & 39 & 14.6 \\
\hline 9 & others & 5 & 1.9 \\
\hline Total & & 267 & 100 \\
\hline
\end{tabular}

It was noted that high level of critically ill patients in missions as agreed by the respondents. The average AED $(56.6 \%)$, high proportion of patients requiring waiting time for victims to be seen was 29.7 minutes. AED admissions ( $53.2 \%$ ), insufficient AED space Common causes (table 2) of long waiting period were $(51.7 \%)$ are also known causes of prolonged AED ad- also noted.

Table 2: Common causes of long waiting time in AEDs

\begin{tabular}{|l|l|l|l|}
\hline S/No & Cause & Value & Percentage \\
\hline 1 & Specialty Pre-review delays & 39 & 14.6 \\
\hline 2 & Theatre delays & 73 & 27.4 \\
\hline 3 & $\begin{array}{l}\text { Shortage of team/specialty specific } \\
\text { bed capacity }\end{array}$ & 69 & 25.8 \\
\hline 4 & Shortage of Consultation rooms & 86 & 32.2 \\
\hline Total & & 267 & 100.0 \\
\hline
\end{tabular}

Causes of poor outcome of care in an overcrowded ac- cident and emergency department are as listed in (table 
Table 3: Common causes of poor outcome of patients' management in AEDs

\begin{tabular}{|l|l|l|l|}
\hline S/No & Cause & Value & Percentage \\
\hline 1 & $\begin{array}{l}\text { Insufficient/faulty monitoring } \\
\text { devices }\end{array}$ & 54 & 20.2 \\
\hline 2 & Theater delays & 80 & 30.0 \\
\hline 3 & Radiological delays & 36 & 13.5 \\
\hline 4 & Haematological delays & 34 & 12.7 \\
\hline 5 & AED personnel fatigue & 55 & 20.6 \\
\hline 6 & others & 8 & 3.0 \\
\hline Total & & 267 & 100.0 \\
\hline
\end{tabular}

Diversion of patients (figure 5) to privately owned clin- ics was not so a major concern of AED overcrowding in this environment.

Figure 5: Diversion of patients away from AED

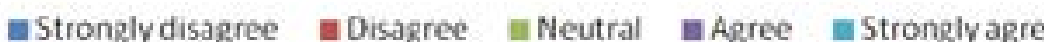

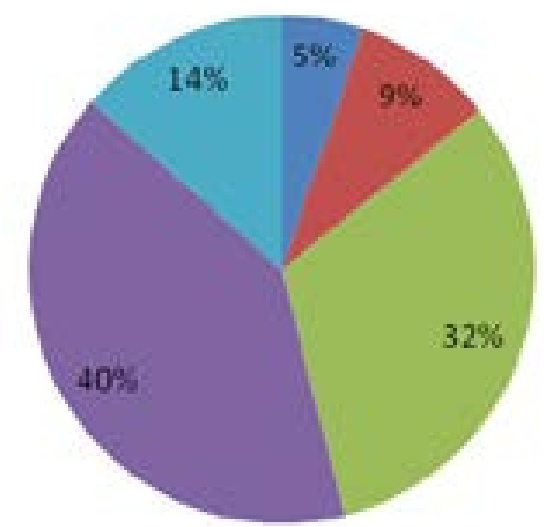

\section{Discussion} The potential dangers of AED overcrowding have re- AED overcrowding include (1) "boarding" of patients cently gathered national and international attention in- in the AED, (2) increased risk of medical errors, (3) amcluding the United States ${ }^{1,4}$. Although no specific defi- bulance diversion, (4) threat to disaster preparedness, nition exists, AED overcrowding refers to an extreme and (5) eroding reliability of the emergency care system. excess of patients in the treatment areas, exceeding The AED is neither designed nor equipped to provide AED capacity and often necessitating medical care to longitudinal care. In our study, high level of critically be provided in AED hallways and other makeshift as- ill patients in AED, high proportion of patients resessment areas. According to a 2002 national US esti- quiring AED admissions, insufficient AED space, are mate, more than $90 \%$ of large hospitals report AEDs also known causes of prolonged AED admissions as agreed by the respondents. Delay in undergoing radiological investigations were due primarily to non availability of personnel on duties, faulty x-ray and/or ultrasounds machines, faulty CT and/or MRI machines and non availability of electric power supply. Common morbidities and mortality from floor patients resulted from poor monitoring, dislodged nasal prungs and face mask. . Overcrowding of AED is considered to be a major cause of poor outcome of patient's management. Therefore, it is important to note that under staffed AED cannot provide adequate or critical care to severey ill patient. Surely, in this circumstance, even to give an undivided attention over a long time will lead to fatigue and this may compromise patients' safety. Furthermore, management of these patients may be so labour intensive that staff in the accident and emergency may hardly pay attention to other AED patients due to fatigue.

Regardless of the proficiency of the AED staff, AED overcrowding is a prime example of a complex problem creating a high risk environment for medical errors and threatening patient safety ${ }^{6,7}$. Timely emergency care is often predicted on speedy ambulance transportation of victims thus, diverting first to an inappropriate hospital due to lack of space in an overcrowded AED may endanger patients by delaying appropriate treatment. The inability to get a free AED will also delay first responders/EMS team in returning to duty and responding to other emergency calls ${ }^{8,910}$. In effect, ambulance diversion endangers anyone who could potentially depend on fast response time ${ }^{9,10}$. Overcrowded AEDs would be ill equipped to handle mass casualty victims in a disaster scenario. As AED utilization continues to increase, ${ }^{11}$, ${ }^{12}$ there is substantial concern that Nigeria AEDs will not be able to meet the growing demand for emergency services. "The current resources supporting emergency care are insufficient to meet the needs of all patients at all times. AED capacities has been stretched to such an extent that the quality of emergency care is reportedly eroding, and reliability of the entire emergency care system in the US has been called into question ${ }^{1,4,13}$. In this study, we found a similar result AED capacities have been over stretched to the extent that the quality of emergency care in Nigeria is not prompt and regular.

In the past, AED overcrowding was attributed to improper use of the AED by a large volume of non-urgent patients. In fact, the total number of AED visits has been reported to have poorly correlated with AED ercrowding ${ }^{1,13}$. The notion that non-urgent patients the leading cause of the AED overcrowding crisis as now been abandoned. ${ }^{1,13-15}$ We now realise that the true causes of AED overcrowding are much more difficult, ${ }^{14}$ and include (1) inadequate inpatient capacity, (2) higher severity of illness, and (3) hospital system estructuring. An aging population and increasing prevalence of high complexity medical problems have increased the severity of illness among AED patients, ${ }^{16,17}$ and this has become a key determinant of AED overcrowding. For example, the number of critically ill patients presenting to California AEDs from 1990 to 1999 increased by $59 \% .{ }^{11,18}$

This sudden increase in critical patients, coupled with a markedly decreased inpatient capacity, forces AEDs to serve as "pseudo-ICUs". In many parts of the world, AED overcrowding has been reported to be linked to poor inpatient bed availability in the Florida (US) ${ }^{19}$ United Kingdom ${ }^{20,21}$ and Australia, and has been recognized as a "global indicator of health care system failure". ${ }^{22}$ Also, long AED admissions, long waiting times as previously reported are known causative factors of AED overcrowding. ${ }^{23}$ In developing countries, othe causes of AED overcrowding, in addition to the above, have been noted to be poorly functioning National health insurance scheme, extreme poverty with absolute lack of money to pay for medical services. Hence, even those patients that are discharged in the AED ward may not pay and leave.

There is no organized trauma or emergency systems to appropriately direct patients to ED. In addition, due to the abundant poverty and ignorance, a lot of patients often present late to the AED, frequently with complications. There is also a failure of supporting health facilities such as the secondary health care and private establishments resulting in overcrowding of the tertiary hospitals AEDs.

Potential solutions for AED overcrowding may affect health care delivery to the emergency department patients internationally ${ }^{7,24}$. Any threat to the integrity of the emergency care system constitutes a public health emergency. Special measures to strengthen AED infrastructure must be taken.

The recommendations include (1) planning for delivery of care to patients who must be placed in temporary bed locations, (2) coordination with long term health 
facilities and home health agencies to facilitate hospital discharges and (3) incorporating AED overcrowding initiatives into system-wide performance improvement goals. The strategic planning initiative is intended to help hospitals expect and prepare for AED overcrowding, rather than react to AED overcrowding after it has occurred

AED overcrowding threatens public health by compromising patient safety and jeopardising the reliability of the entire US emergency care system ${ }^{1,4,19}$. AED overcrowding is an indication of health care system failure on many levels. The main cause of AED overcrowding is a failure to ensure adequate inpatient capacity for an AED population with increasing severity of illness. $\mathrm{Al}$ leviating the overcrowding crisis will require a multidisciplinary system-wide approach ${ }^{25}$.

AED overcrowding has been a difficult problem deeply rooted in "issues related to inpatient capacity, inadequacy of alternatives for hospitalization, and hospital resource shortages ${ }^{25,26}$

Frustrations of staff and patients are enormous. In our study, outcome of patients who have expressed dissatisfaction revealed, will not come back at all, may come back if the need arises, will always come back. Outcome of frustration expressed by the AED personnel revealed, Work not appealing, Need motivator, still coping, Normal. Diversion of patients (figure 5) to privately owned clinics was not so a major concern of AED overcrowding in this environment. To relieve overcrowding and thus ensure the safety of AED patients, communities struggling with AED overcrowding must tackle the crisis with a multidisciplinary system-wide approach. ${ }^{26}$ Fatigue has been noted to be associated with reduced performance, clumsiness, changes in mood, errors, and patient harm. ${ }^{27}$ In Health care worker, fatigue is an invisible term associated with patient safety and medical errors. ${ }^{28,29}$ To reduce resident physician schedules, allowing for shorter shifts and more sleep, can improve diagnostic and medication errors in an acute care setting.

community to avoid AED attendance, prevention of could reduce AED overcrowding. Importantly also, is to prevent or reduce access block to AED ${ }^{5}$. Therefore, allocating resources to reducing AED overcrowding should be one of the higher priorities in medical emergency care.

\section{References}

1. S Trezeciak, E P Rivers. Emergency department overcrowding in United States: an emerging threat to patien safety and public health. Emerg Med J 2003; 20: 402-405 2. American Academy of Pediatrics Overcrowding Crisis in Our Nation's Emergency Departments: Is Ou Safety Net Unraveling? Pediatrics 2004; 114;878 DOI 10.1542/peds.2004-1287 http://pediatrics.aappublications.org/content/114/3/878.full.html(Accessed 22nd December,2012)

3. J B McCabe. Emergency department overcrowding: A national crisis. Academic medicine 2001; 76: 672-674 4. Lewin Group (for the American Hospital Association). Emergency department overload: a growing crisis. The results of the American Hospital Association Survey of Emergency Department (ED) and Hospital Capacity. Falls Church, VA: American Hospital Association, 2002

5. D M Fatovich, Y Nagree, P Sprivulis. Access block causes emergency department overcrowding and ambulance diversion in Perth, Western Australia. Emerg MedJ 2005; 22:351-354. Doi: 10.1136/emj.2004.018002 6. Weissman JS, Rothschild JM, Bendavid E, Sprivulis P, Cook EF, Evans RS, et al. Hospital workload and adverse events. Med Care. 2007; 45(5):448-455

7. Namita Jayaprakash, Ronan O'Sullivan, Tareg Bey, Suleman S. Ahmed, Shahram Lotfipour, Crowding and Delivery of Healthcare in Emergency Departments: The European Perspective. West J Emerg Med. 2009; 10:233-239

8. Litvak E, Long MC, Cooper AB, et al. Emergency department diversion: causes and solutions. Acad Emerg Med 2001; 8:1108-10

9. Brewster L, Rudell L, Lesser C. Emergency room Increasing the availability of acute care beds ${ }^{30}$, better diversions: a symptom of hospitals under stress. Issue home care, and intense nursing home placement of the brief: findings form the HSC. Washington, DC: Center elderly, better organized, and diligent discharge plan- for Studying Health System Change, 2001

ning, speedier assessments in the AED, for example, 10. Schull MJ, Morrison LJ, Vermeulen M, et al. improved turnaround times for laboratories, radiolo- Emergency department overcrowding and ambulance gy, and consultations ${ }^{31-33}$. Speedier move to different transport delays for patients with chest pain. CMAJ. admitting wards if admitted, better care of AED bed 2003;168:277-283.

capacity, better management of chronic disease in the 11. Lambe S, Washington DL, Fink A, et al. Trends in the use and capacity of California's emergency departments, 1990-1999. Ann Emerg Med 2002: 39:389-96 12. Modernisation Agency. Improving the flow of emergency patients. 2001. (www.modern.nhs.uk) (accessed on 2nd December, 2012)

13. Derlet RW. Overcrowding in emergency departments: increased demand and decreased capacity. Ann Emerg Med 2002; 39:430-2.

14. Gordon JA, Billings J, Asplin BR, et al. Safety net research in emergency medicine: proceedings of the Academic Emergency Medicine Consensus Conference on "The Unraveling Safety Net". Acad Emerg Med 2001;8:1024-9

15. Joint Commission on Accreditation of Healthcare Organizations (JCAHO). Sentinel event alert, June 17, 2002. http://www.jcaho.org/about+us/news+letters/ sentinel+event+alert/sea_26.html (accessed 21 Sep 2002)

16. Joint Commission. Sentinel Event Alert, June 17, 2002: delays in treatment. Available at www.joint commission.org/SentinelEvents/SentinelEventAlert/ sea_26.htm. Accessed July 20, 2008

17. Cowan RM, Trzeciak S. Clinical review: emergency department overcrowding and the potential impact on the critical ill. Crit Care. 2005; 9(3):291-295

8. Kelen GD, Scheulen JJ, Hill PM. Effect of an emetgency department (ED) managed acute care unit on ED overcrowding and emergency medical services diversion. Acad Emerg Med 2001; 8:1095-100.

19. Derlet RW, Richards JR. Emergency department overcrowding in Florida, New York, and Texas. South Med J 2002; 95:846-9.

20. Department of Health (UK). Reforming emergency care-practical steps, 2001. http://www.doh.gov.uk/ emergencycare/reform.htm (accessed May 2003

21. Walford S. Unexpected medical illness and the hospital response. Models of emergency care. Warwick: University of Warwick, 2002. (www.emergencycare. Org.uk) (accessed on accessed 22nd September, 2011) 22. Graff L. Overcrowding in the ED: an internation symptom of health care system failure. Am J Emerg Med 1999; 17:208-9
23. British Medical Association. Waits and measures: mproving emergency care for today's patients. London, BMA, 2002. (wwwbma.org uk) (accessed 8th December, 2012)

24. Solberg LI, Asplin BR, Weinick RM, Magid DJ mergency department crowding: consensus development of potential measures. Ann Emerg Med. 2003; 42:824-34

25. Forster AJ. An agenda for reducing emergency department crowding. Ann Emerg Med. 2005; 45: 479- 81. 26. Schull MJ, Slaughter PM, Redelmeier DA. Urban erency department overcrowding: defining the problem and eliminating misconceptions. Can J Emerg Med. 2002; 4:76-83

27. Parshuram CS. The impact of fatigue on patient safety. Pediatr Clin North Am. 2006; 53(6): 1135-1153 28. Shojania KG, Duncan BW, McDonald KM, Wachter RM. Safe but sound: patient safety meets evidence-based medicine. JAMA. 2002; 288(4):508 -513

29. Kathy N. Shaw, Richard M. Ruddy, Cody S. Olsen, Kathleen A. Lillis, Prashant V. Mahajan, J. Michael Dean and James M. Chamberlain. Pediatric Patient Safety in Emeroency Departments: Unit Characteristic and Staff Perceptions. Pediatrics 2009; 124;485; DOI: 10.1542/peds.2008-2858

30. Meyer GS, Massagli MP. The forgotten component of the quality triad: can we learn something from "structure"? It Comm I Oual Improv. 2001; 27(9):484-493 31. N C Proudlove, K Gordon, R Boaden Can good bed management solve the overcrowding in the accident and emergency departments Emerg Med J 2003; 20:149-155

32. M J Bullard, C Villa-Roel, K Bond, M Vester, R H Brian and H R Brian. Tracking emergency department overcrowding in a tertiary care academic institution. Healthcare quarterly 2009; 12: 99-106 www.longwoods. com (Accessed on 16th December, 2012)

33. Shafe M. Staffing your emergency department appropriately and efficiency? Presented at the American College of Emergency Physicians Scientific Assembly; September 29, 2005; Washington, DC 